\title{
ECONOMISTAS Y JURISTAS EN LA PUGNA ENTRE ESTADO SOCIAL, ESTADO DE DERECHO: RECUPERACIÓN DE UN DEBATE
}

Economists and jurists in the struggle between the Social State \& the Rule of Law: recovery of a debate

José EUGenio Soriano García* UNIVERSIDAD COMPLUTENSE MADRID, ESPAÑA

\footnotetext{
* José Eugenio Soriano García, Catedrático de Derecho Administrativo. Correo electrónico: <jsorgar@gmail.com>.
}

Artículo recibido el 22 de enero de 2017 y aceptado para publicación el 16 de marzo de 2018. 
RESUMEN: No cabe democracia fuera del Estado de Derecho. Todo intento de evitar la ley acaba en puro asambleísmo. En consecuencia, Economía y Derecho han de caminar juntos porque no hay eficiencia en contra de la ley. Por ello es importante mostrar las diferencias entre una y otra ciencia. La clave para unir en sus objetivos a estas dos débiles ciencias es la dignidad de la persona, a cuyo servicio han de cooperar resueltamente ambas.

Palabras Clave: economistas y juristas, diferencias, Estado Social, Intervención económica, Estado de Derecho, dignidad de la persona.

ABSTRACT: There is no democracy outside the Rule of Law. Any attempt to avoid the law, ends in pure populism. Accordingly Economy and Law have to walk together, because there is no efficiency against the law. Therefore it is important to show the differences between one and another science. The key to uniting these two weak sciences in their objectives is the dignity of the person, in whose service both will cooperate resolutely.

KEYWORDS: economists and jurists, differences, Social State, economic intervention, Rule of Law, dignity of the person. 
"¿Entonces debo adherirme al Partido Laborista? Superficialmente esto es más atractivo. Pero si bien se mira hay grandes dificultades. Para empezar, es un partido de clase, y la clase no es la mía. Si he de perseguir intereses sectoriales, perseguiré el mío propio. Cuando se llega a la lucha de clases como tal, mi patriotismo local y personal, como los de cualquier otro, excepto algunos entusiastas desagradables, está vinculado a mi propio ambiente. Puedo estar influido por lo que me parece ser de justicia y buen sentido, pero la guerra de clases me encontrará del lado de la bougeaisie ilustrada"1.

1. La relación entre estas dos ciencias débiles o desmayadas, Economía y Derecho ${ }^{2}$, es de por sí problemática ya que entre el dogma y la racionalidad existe en la práctica -y es obvio- un campo de valoración y examen que corre siempre el peligro de caer en la tentación de la mera opinión. Y ello, cuando sucede, desvaloriza el juicio ofrecido. Y es clave examinar las relaciones entre ambos órdenes académicos desde el momento en que en el fondo, de alguna manera, responden a la tensión propia entre la regla de justicia y la de eficiencia, y con ello, aun dando pasos demasiado grandes, también entre el Estado y el mercado. Estado que no puede actuar en el mundo occidental si no es a través del Derecho, frente a un mercado, global, que no vacila en crear sus propias reglas no siempre coincidentes con las del orden jurídico.

Este riesgo se produce además con mayor frecuencia de la esperada, ya que con la invasión de la política (con minúscula), los medios (especial-

MAYNARD (1988) p. 300.

2 Admito de forma meramente retórica que pueda hablarse del Derecho como ciencia; en realidad no es así como pienso. Más bien entiendo que es un arte, consistente en lograr la realización de una virtud dificilísima de teorizar, la Justicia. Y hacerlo con técnicas como la interpretación, la lógica, la historia, etc., lo que no quita un ápice para su mayor importancia, ya que esta convención en que el Derecho consiste es la que distingue resueltamente entre un mundo civilizado y otro que, simplemente, no lo es. Economía y Derecho, no obstante, aportan racionalidad cuando son metodológicamente bien empleadas, sin futuribles ni contraseñas vacías de contenido traspasadas de contrabando como si fueran parte de la argumentación, intentando que no sea meramente la pasión y la emoción las que determinen como fuerzas incontrolables la organización y el funcionamiento de la sociedad. 
mente la televisión), las redes sociales y el populismo asociado a ellas, parece que todo el mundo sabe de Derecho y de Economía. Basta asomarse a cualquier tertulia para comprobar cómo cualquier indocumentado se pone a pontificar, hablar y aconsejar como si estuviera en un púlpito y hablara ex catedhra.

Ello conlleva una cierta desgana, incluso depresión, a la hora de examinar con método académico las relaciones que se producen en torno a ambas disciplinas académicas. Y que hay que recuperar, en torno a la exigencia de un cierto rigor, ya que el debate que se produjo durante los años noventa del pasado siglo en torno a las relaciones entre el Estado y el mercado, y al final entre lo que es Estado de Derecho y los adjetivos que lo han ido adornando, producen como cuestión evidente que tales calificativos amenazan con sepultar el exacto contenido de lo que es, resueltamente, la mejor y más cualificada aportación del pensamiento a la configuración de la institución que organiza con éxito tales relaciones. Y que no es otra institución que el propio y sencillo Estado de Derecho.

Cuando se le empieza a apellidar como Social, Democrático, Cultural, Ambiental, etc., lejos de enriquecer su contenido, sucede que se elevan tales cualificaciones sobre el genuino elemento que sirve para organizar con bastante exactitud la tensión entre seguridad, libertad e igualdad ${ }^{3}$. Y éstos son, con toda evidencia, los fundamentos últimos de toda relación de poder y de convivencia.

Es obvio que los temas de nuestro tiempo, tales como la explosión demográfica, el agotamiento de los recursos, cambio climático, la mundialización y digitalización del trabajo y de la economía, la definitiva igualdad de hombre y mujer, la universalización de la dignidad humana y tantos otros, exigen atención inmediata y continua. Y en consecuencia, que todas las políticas acaben centrándose en tales objetivos. Ahora bien, ello se hace directamente en el nivel legal, reglamentario, regulador, sin descubrir mediterráneos que hace ya muchos siglos se conocen. No hay que adjetivar, como si fuera un mantra, cada aportación que obligue a dirigir las políticas hacia un objetivo, ya que nunca se acabaría y, sobre todo, aparecería inmediatamente la idea de comprometer todo el sein del Estado en cada uno de esos supuestos objetivos. No cabe, hay que insistir, calificar al Estado de Social, Democrático, Ecológico, Feminista, Digno,

Severo (1977) pp. 205-222, Mancur (2001) y Robinson (2012). 
Ambiental, Cultural y así continuar en un bucle melancólico añadiendo una política como definición del Estado. Eso, más bien, acaba apuntando a la generación de grupos de intereses asociados a una ideología que se pretende que tenga superioridad epistemológica y moral para impedir, exactamente, el debate de las ideas.

No creo que a esta altura del siglo xxı, más allá de los populismos generados por la crisis económica (especialmente preocupante en Europa, donde el fenómeno es nuevo) o unidos a factores culturales, se pueda fácilmente cuestionar que sin Estado de Derecho, la democracia concluya en otra cosa que en puro asamblearismo y acción directa. Estas dos actitudes suponen la propia destrucción, precisamente, de la seguridad, libertad e igualdad.

Es el Estado de Derecho, con su trilogía clásica de separación de poderes, respeto a las minorías y sociedad abierta, basado en la pura dignidad de la persona y con la aceptación completa de las sentencias del Poder Judicial, el que tiene que irse ocupando de todos y cada uno de esos temas de nuestros días. Algunos esenciales y con clara proyección al futuro, tanto que se incorporan continuamente a las distintas políticas, pero realizadas desde las diferentes ópticas ideológicas, cada una con su aportación. Nunca estableciendo un paradigma de resultados y de aproximaciones ideológicas y políticas que pretendan pasar de contrabando su característica como inderogables. La discusión ha de estar siempre abierta, atenta a los resultados, observadora de las nuevas aportaciones tecnológicas que tanto pueden cambiar las políticas y exigiendo de acuerdo con el puro Estado de Derecho que se sometan al juicio público que supone el mercado de las ideas y su evidente contraste judicial.

De ahí que haya que volver la noria al punto de partida y de nuevo recomenzar la discusión que la crisis económica pareció querer acabar y que los populismos de todo tipo, en Europa y América principalmente (en el resto de los continentes, grosso modo y con excepciones, hay que tener otra aproximación), quieren acallar intentando demoler la democracia representativa, siempre perfectible e incluso en crisis, pero que supera con mucho a las fórmulas de democracia directa, que en realidad esconde un programa de eliminación del disidente ${ }^{4}$. Por supuesto que la única

4 VOLPE (1977). Y como reflexión general, la obra de Giovanni Sartori, aquí en especial. SARTORI (2015), La corsa verso ilnulla, Mondadori, en traducción de SARTORI y PetIT (2016). 
forma de mantener una sociedad estable es lograr un consenso medio basado en la esperanza de un mínimo de bienestar. Pero esa necesidad, además creciente, no se consigue simplemente adjetivando como "social" al Estado. Aun más, de hecho, procede del Estado autoritario que logró y en gran medida descubrió el Canciller Otto von Bismarck. Absolutamente necesario el objetivo de atender a la modulación de la igualdad en la sociedad, la denominación como Social se ha impuesto, si bien a partir de ahí son políticas concretas las que día a día van logrando los objetivos de mantenimiento de la sociedad, cuyos excesos, por otra parte, también son manifiestos. En definitiva, se logran estos objetivos con una legislación adaptada a las circunstancias y que cada vez resulta más necesaria, pero siempre partiendo del Estado de Derecho, auténtico fundamento de éstas y de las demás políticas de nuestros días.

Este debate ha quedado aparentemente sepultado y apenas se oye con sordina impuesta por la crisis económica, lo que ha obligado a mirar sólo las exigencias de recuperación económica y financiera. Pero se han ido olvidando todo el importante resto de temas y asuntos, como los descritos antes, y que son hoy bienes públicos de primera magnitud (medio ambiente, cultura, justicia, género, clima, etc.). Es cierto que en el nivel administrativo han continuado regulándose por el Estado y su Administración, pero el gran debate quedó arrumbado y enterrado. Siendo así, hay que recuperar por completo la situación de estas cuestiones en el primer frente de todo debate, ya que la economía no lo resuelve todo. La economía y su estabilidad son absolutamente imprescindibles; desde luego sin ellas, lo que se produce es la pura destrucción de la sociedad y el ascenso de los populismos de todo orden ${ }^{5}$. Ahora bien, enfocado el problema económico, no cabe dispersar los demás grandes temas, esencialmente políticos (pero que tienen que acabar teniendo una definición jurídica), cuyo olvido mismo está en el origen de los graves problemas, también políticos, que contaminan la sociedad.

Este tema tiene que ser reabierto. Hay que volver a situarlo en la primera línea de fuego intelectual y por ende social. No podemos seguir mirando cada uno de los grandes temas anunciados como si fueran asuntos independientes, merecedores por sí mismos de un tratamiento único. Hay que examinarlos dentro del Estado de Derecho y exigir que los añejos moldes

5 Kershaw $(1983,1990$ y 2017). 
vuelvan a recibir el buen vino de la discusión. Si no se sitúan los grandes temas dentro exactamente de los problemas que tiene que resolver el Estado de Derecho, no se dará un paso definitivo para resolverlos y quedará cada uno de ellos sometido a una discusión especial, sin garantías de que tienen un encaje dentro de unos parámetros que han demostrado su eficacia y acierto durante dos siglos largos.

Volvamos pues a examinar las relaciones entre estas dos ciencias que están detrás de la formulación del Estado de Derecho y del mercado, y por ende, de la democracia.

De ahí que por nuestra parte, nos limitemos a valorar, con la técnica jurídica, las aportaciones de los economistas, que cuentan con técnicas claramente diferenciadas.

Debo así recordar que un jurista puede tener unas claves interpretativas de la realidad harto lejanas del economista en muchas ocasiones. Hay, al menos, tres grandes razones para diferenciar entre unos y otros científicos sociales, si se me permite este pomposo calificativo.

En primer término, el jurista no puede escapar del ordenamiento jurídico y el economista no está preso de él. Si el economista considera las instituciones como endógenas, naturalmente queda sometido al juego de las instituciones jurídicas, pero será una opción o hipótesis científica, no una exigencia imprescindible. Siempre puede trabajar ofreciendo alternativas a la regulación, lo que los juristas en nuestro lenguaje particular denominamos de lege ferenda. Por consiguiente, las alternativas a las situaciones encontradas pueden ofrecerse al economista como un terreno virgen en el que sembrar exclusivamente sus ideas, mientras que el jurista se va a encontrar con un terreno colonizado por el Derecho, roturado por la ley, en el que la plantación que haga tiene los aperos, cultivo y clima ya dados. Así, por poner un ejemplo, podrá al jurista gustarle o no la planificación económica, pero aunque la rechace, puede toparse de bruces con el artículo 128 de la Constitución que le resultará inesquivable. El jurista tiene como lectura obligada el B.o.E. (y hoy los 17 boletines autonómicos), mientras que el economista vive habitualmente enfrascado feliz en lecturas más fértiles y atractivas. 
El trabajo de JAMES M. BuCHANAN “ ¿Ha perdido la economía su camino?”6, plantea con toda su crudeza y con pasión las relaciones entre esta "ciencia suave" y el entramado institucional. La falta de una visión integradora en el trabajo de los economistas y la reducción del trabajo de éstos a juegos intelectuales que no aportan ninguna comprensión del fenómeno humano, tan ligado a prescripciones normativas, es asumida como una crítica muy sagaz por este Premio Nobel.

En segundo lugar, el jurista vive angustiado por el corto plazo. Resolver el problema del cliente en un término dado es parte de su trabajo habitual. El economista, por el contrario, puede confiar más en la racionalidad económica que no ha de ser cortoplacista, puesto que en muchas ocasiones la formación de los mercados y la respuesta que éstos den actúa en el largo plazo. Así, por ejemplo, un problema de consumo para el jurista puede tener que resolverse en el inaplazable espacio de 20 días si tiene que interponer una demanda, mientras que el dichoso economista puede contemplar satisfecho cómo el mercado va acompasándose a las respuestas que la oferta y demanda de calidad de un producto le merece, con abstracción absoluta de si fracasa o no la pequeña demanda (dicho sea en términos procesales) del cliente del bufete.

En tercer lugar, el jurista se ocupa de los ciudadanos, de las personas, una a una, puesto que sus problemas individuales son los que entran por la puerta de su despacho. De esta forma, los principios jurídicos resultan de la agregación de problemas individuales, método jurídico bastante acreditado ${ }^{7}$, con ilustres precedentes ${ }^{8}$ y difusión en prácticamente todo el mundo jurídico anglosajón ${ }^{9}$. Se trata así de superar una mentalidad cartesiana o tomista, categórica, apriorística que se aproxima dogmáticamente a la realidad externa desde unas categorías internas previamente concebidas que forman entre sí la supuesta trama de un "sistema" y, por el contrario, se trata de dar paso a la experiencia, a la fórmula de "prueba y error" y cuando ya se tiene una experimentada línea, entonces pero sólo entonces, extraer el correspondiente principio jurídico. Nótese que la base de este método es, al final, el caso concreto. Es sobre la base de

\footnotetext{
6 BuChANAN (1997).

7 VIEHWEG (1964).

8 Vico y Veneziani (1708).

9 NOVICK (1990).
} 
múltiples casos cuando se obtiene, tras deducir sus elementos principales, el principio general que luego, a su vez, retorna sobre la realidad y logra ofrecerse como un conjunto bien acreditado de antecedentes, ilustrado por numerosos precedentes perfectamente identificados, para resolver los asuntos futuros. Hay, por así decir, menos "modelos" en los que haya que empezar con un "supongamos...". No se supone sino que se afirma, a partir de algún caso concreto, y luego por deducción se puede llegar a conocer cuál es el principio de base que inspira el resultado al que se llega y se proyecta sobre la ley.

Estas tres diferencias han de ser muy tenidas en todo trabajo que contabilice entre sus presupuestos el estudio de trabajos jurídicos y económicos.

Añadamos: por nuestra parte, hace ya tiempo que venimos defendiendo, como recordamos en nuestra primera nota a pie de página, que, propiamente dicho, el Derecho no es una ciencia, lo que no quita un ápice ni su importancia ni su raciocinio. Aun más, sin Derecho, con mayúscula, no existe la menor posibilidad de convivencia básica que permita construir todo el resto del devenir personal y social. Pero no hay que afirmar que deja de ser un arte, que desarrolla técnicas, para realizar algo tan complejo como aplicar individual y colectivamente una virtud moral como es la justicia. De ahí que difícilmente pueda compararse con las tradicionales formulaciones propias del conocimiento científico. Nuestras armas son una suma compleja, a veces complicada, de lógica, historia, argumentación, analogía, etc., todas ellas en sí mismas valiosas, tanto que quien queda fuera de ellas queda, a su vez, fuera totalmente del orbe civilizado y entra, sin más y directamente, en la sinrazón, la coacción, la violencia y el miedo. Exactamente lo que se pretende evitar con este modesto instrumento que es el Derecho. Esta magnífica joya de la mejor orfebrería social y humana establece claramente la diferencia entre quienes juegan con reglas que permiten continuar viviendo, y quienes rompen esas mágicas fórmulas que impiden, simplemente impiden, continuar su existencia pacífica y normal. Esta es su importancia, más allá de disputas sobre su "cientificismo".

2. Creemos firmemente, junto con tantos otros que son legión, que la realización del capitalismo debe enmarcarse dentro del Estado de Derecho. De ahí la importancia del dato jurídico a la hora de construir las instituciones que necesita la economía de mercado, lo cual conlleva, a su vez, que 
democracia y Estado de Derecho son términos de una misma ecuación, ninguno de los cuales puede conjugarse por separado.

Mario Vargas Llosa, en un brillante artículo ${ }^{10}$ hace ya casi veinte años, nos dijo sobre la dimensión unitaria de la defensa de la libertad (faltaba entonces Venezuela) ${ }^{11}$ : "A diferencia del señor Kaplan, los liberales no creemos que acabar con el populismo económico constituye el menor progreso para una sociedad, si, al mismo tiempo que libera los precios, recorta el gasto y privatiza el sector público, un gobierno hace vivir al ciudadano en la inseguridad del inminente atropello, lo priva de la libertad de prensa y de un poder judicial independiente al que pueda recurrir cuando es vejado o estafado, atropella sus derechos y permite que cualquiera sea torturado, expropiado, desaparecido o asesinado según el capricho de la pandilla gobernante. El progreso es simultáneamente económico, político y cultural o, simplemente, no es. Por una razón moral y también práctica: las sociedades abiertas, donde la información circula sin trabas y en las que impera la ley, están mejor defendidas contra las crisis que las satrapías, como lo comprobó el régimen mexicano del PRI hace algunos años y lo ha comprobado hace poco, en Indonesia, el general Suharto. La influencia determinante de la falta de una genuina legalidad en la crisis de los países autoritarios de la cuenca del Pacífico no ha sido suficientemente subrayado. ¿Cuántas dictaduras eficientes ha habido? ¿Y cuántas ineficientes que han hundido a sus países a veces en un salvajismo pre-racional como en nuestros días les ocurre a Argelia o Afganistán? La inmensa mayoría son estas últimas; las primeras, una excepción. Es una temeridad optar por la receta de la dictadura en la esperanza de que sea eficiente, honrada y transitoria, y no lo contrario, a fin de alcanzar el desarrollo. Hay métodos menos riesgosos y crueles para alcanzarlo, pero gentes como el señor Kaplan no quiere verlos. No es cierto que la 'cultura de la libertad' sea una tradición de largo aliento en los países donde florece la democracia. No lo fue en ninguna de las democracias actuales hasta que, a tropiezos y con reveses, estas sociedades que optaron por la cultura fueron per-

10 VARGAS (1998).

11 Sobre Venezuela existe un continuo y muy relevante conjunto de trabajos del profesor Alan Brewer-Carías, cuya lectura es obligada para quien quiera conocer de primera mano lo que significa una tiranía populista. Recomiendo vivamente visitar su portal en Internet donde pueden encontrarse, generosamente cedidos por el autor al público, notables aportaciones sobre este asunto que ofrecen un vivo y enérgico conjunto de argumentaciones sobre la defensa de la libertad individual y colectiva. 
feccionándola en el camino, hasta hacerla suya y alcanzar gracias a ello los niveles que tienen actualmente".

Estas palabras del excelente escritor nos animan a transitar en esta bifurcación, porque vienen a mostrar que al final existe una clara sintonía entre quienes, utilizando conocimientos sociales, acaban trabajando al servicio de las ideas que conducen directamente a la consolidación del Estado de Derecho.

El Premio Nobel de Economía Amartya Sen, desde una posición ideológica aparentemente bien distinta, confirma este diagnóstico cuando nos recuerda12: "La democracia y la libertad son buenas para la economía. Evitar desastres económicos como el hambre se ha hecho mucho más fácil gracias a la existencia y el ejercicio de las distintas libertades y derechos políticos, entre los que se encuentra la libertad de expresión. En realidad, uno de los hechos más notables en la terrible historia del hambre es que nunca ha habido una hambruna importante en ningún país con una forma democrática de gobierno y con una prensa relativamente libre".

Y es que no hay economía abierta, a largo plazo, si la sociedad no es abierta $^{13}$. De abrir esa economía y buscar las causas por las que han existido tradicionalmente en nuestro país intentos de que se produzca la apertura de la sociedad sin que simultáneamente se abra la economía, o más precisamente las libertades económicas, trata esta breve aportación, hecha desde la perspectiva del Derecho. Veremos que, como cabría esperar, en nuestros días la gran polémica sobre el papel que han de ocupar las libertades económicas y la consiguiente lucha por superar las dificultades para que sean reales y efectivas, tiene muy bien definido el escenario. De una parte se sitúan aquellos que piensan que hay que utilizar el Estado, el poder público, para construir la felicidad de los demás. Y de otro se sitúan aquellos que entienden que debe existir un Estado que defina un marco en el que cada cual busque por sí mismo la propia prosperidad ${ }^{14}$.

12 El País, viernes 14 de octubre de 1998. Desarrolla ahí sus clásicos temas sobre la justicia en contraposición con Rawls, a cuya memoria sin embargo dedica el libro básico sobre su concepción de lo justo. Vid. SeN (2009).

13 POPPER (2006).

14 "We hold these truths to be self-evident, that all men are created equal, that they are endowed by their Creator with certain unalienable Rights that among these are Life, Liberty and the pursuit of Happiness". Segundo párrafo de la Declaración de Independencia de los Estados 
De un sitio están los que apuestan sólo por la mayoría. De otro, quienes aceptan también los derechos de la minoría como regla política y como norma jurídica. De un lado, los arquitectos que construyen la fábrica de la dicha de los demás. De otro, los maestros de obra de su propia edificación.

La utilización de las aportaciones de los economistas, tomadas en serio, alumbra potentemente el análisis jurídico, mostrando cómo algo que debería ser obvio, a saber, que las libertades económicas forman parte de la libertad en general y que ésta no puede existir sin aquéllas, ha quedado difuminado y oscurecido por décadas de pensamiento monótono de corte keynesiano, cuya influencia sobre los juristas tradicionales es inconmensurablemente mayor de lo que siquiera sospechan, permitiendo así una actitud esquizoide en la práctica jurídica cuando de ejercer los derechos económicos se trata ${ }^{15}$. Y es que habitualmente el saber económico común, tan ponderado políticamente, no es saber sino tendencia social, prejuicio, quizás en no pocas ocasiones puro sentimiento y emoción, pero totalmente alejado de la racionalidad que ofrece la realidad.

Asimismo, se subraya la exigencia de que las libertades económicas no pueden ejercitarse fuera del marco propio del Estado de Derecho, mostrando la aberración del capitalismo autoritario, fórmula histriónica y remedo de la economía de mercado que desemboca fatalmente en una paranoia política totalmente alejada de una concepción ética fundamental al capitalismo ${ }^{16}$. Recuperar el papel vigilante y regulador al servicio de objetivos públicos iguales para todos en el ámbito de la legislación es parte del cometido teórico de cualquier trabajo que pretenda examinar con objetividad la legislación y la ejecución administrativa de la misma.

3. Nos ocuparemos ahora del Derecho Público, más precisamente del Derecho Administrativo. Bacon indicaba en sus aforismos "ius publicum sustinet ius privatum". Veamos por qué.

Unidos, redactada inicialmente por Tomas Jefferson, con correcciones de John Adams y Benjamin Franklin. MUÑOZ (2016).

15 Con un significado coincidente en alguna medida, más dirigido al exceso y saturación de normas, vid. MARTín-Retortillo (1994) pp. 201-206.

16 Suele olvidarse, por muchas razones, que es precisamente Adam Smith quien se ocupa de la solidaridad y condena del egoísmo. SMITH (2004). 
Vamos a hacerlo justamente en el contexto del pensamiento político dominante desde la Segunda Guerra Mundial, esto es, el llamado "Estado Social y Democrático de Derecho", que es el que inspira continuamente la legislación. La fórmula del Estado Social resulta triunfante en prácticamente todo el viejo continente gracias, entre otras, a las aportaciones del "condenado liberal" con una de cuyas citas encabezamos este capítulo ${ }^{17}$.

"Keynes nos enseñó a despreciar el ahorro"18. Así podría comenzar un curso de Historia del Pensamiento Económico de la posguerra. Sin duda fue el padre de las ideas que mayor poder otorgó al Estado democrático al establecer que el gasto público es lo propio de un Estado civilizado. El "santo horror al déficit" del tradicional Estado liberal saltó hecho trizas por las aparentemente bien fundadas teorías de este aristócrata formado en Cambridge ${ }^{19}$. HAYEK claramente señaló "la idea fatal de que el desempleo se debía fundamentalmente a la insuficiencia de demanda agregada" como idea desastrosa para el porvenir de la economía ${ }^{20}$. Esto es, reducidamente, lo que hizo Lord Keynes. La "aberración keynesiana", como la define BUCHANAN" ${ }^{21}$, y su tragedia "consiste en una enorme cortedad a la hora de proponer remedios frente a las instituciones existentes, al mismo tiempo que impulsa el deseo de sustituir las valoraciones del mercado por controles políticos sobre determinados elementos elegidos (empleo, inversión)".

Otro "Lord", supuestamente liberal en el plano político también, Beveridge, culminaría, asimismo en Inglaterra, con su conocido "Informe", la

17 MAYNARD (1988) p. 3O0, cita con la que se encabeza esta aportación.

18 BUCHANAN Y WAGNER (1983).

19 MAYNARD (1996 y 1937). Su recomendable trabajo The Road from Serfdom, 1995, explica la ligazón entre el keynesianismo y el crecimiento de los sentimientos populares sobre las bondades del colectivismo. El descubrimiento en la Biblioteca de la Universidad de Cambridge de algunos manuscritos antisemitas de nuestro autor, corrobora que el prejuicio ideológico no era algo extraño al exquisito gusto intelectual que profesaba. Muy a propósito, PeACOCK (1995), p. 21, señala: "Estaba imbuido de lo que los teóricos de la elección pública, como BuCHANAN, BURTON, WAGNER y más tarde ROWLEY, Ilamaron 'mentalidad de Harvey Road': espíritus intelectuales afines que creían que el Reino Unido iba a ser y debía ser gobernado por una aristocracia intelectual -es decir, ellos-que podría persuadir al público y a los políticos para que obedecieran sus prescripciones".

Forsthoff (1958). El autor, asimismo, entiende que el Estado de Derecho es el verdadero signo institucional, el único organigrama válido, sin apellidos.

20 HAYEK (1975).

21 BuCHANAN (1997) p. 8. 
obra jurídica y política de quienes estaban dispuestos a asaltar al Estado para conseguir a través suyo penetrar y dominar la sociedad ${ }^{22}$.

La dominación estatal de la economía y de la sociedad, rompería los mecanismos clásicos del Derecho, que se basaban en trazar la raya jurídica entre Estado y sociedad ${ }^{23}$. La "libertad de los modernos", frente a la "libertad de los antiguos", había consistido en levantar un muro impenetrable al poder, un recinto estanco insusceptible de penetración y de mirada por los agentes del poder ${ }^{24}$.

En efecto, las libertades de la Antigüedad clásica y su continuación en el Medievo no partían en realidad de la autonomía de los individuos. Existía una "adecuación de la conducta humana a un orden natural o divino situado más allá de las decisiones del sujeto. Resulta ilustrativo el razonamiento del intelectualismo moral nacido del pensamiento de Sócrates y ampliamente utilizado por la filosofía clásica y cristiana. La acción humana no puede buscar sino el bien ('aquello a que todas las cosas tienden', decía Aristóteles). Si hacemos el mal es porque lo confundimos con el bien y en ese sentido estamos haciendo lo que no queremos, por lo cual la maldad se identifica con la ignorancia, que es la verdadera enemiga de la libertad. Así que obligar a alguien a realizar el bien no implica atentar contra su libertad, sino conducirlo, aun contra sus deseos, a cumplir su papel en el orden verdadero. El hombre realmente libre será, por tanto, aquel que sólo pueda hacer el bien, que, una vez conocido, atrae inevitablemente a la voluntad humana. Dios será así el paradigma de toda libertad: su omnipotencia no incluye -más bien excluye-la posibilidad de obrar mal, ya que su sabiduría es infinita y se identifica con el Bien absoluto"25.

Esto es, precisamente, lo que queda puesto en cuestión en la nueva "libertad de los modernos". No se había tratado meramente de "participar" en el proceso de formación de la voluntad pública, como era el caso de la libertad ateniense propia de los antiguos ${ }^{26}$. Se había logrado que el Estado

22 BeVeridge (1944).

23 Hutchison (1977). Se demuestra en el trabajo que peor que Lord Keynes fueron sus seguidores y apologetas.

24 Constant (1819). Discurso pronunciado en el Ateneo de París en 1819; Diez (1973), pp. 277 y siguientes. CerRoNi (1972).

25 Klappenbach (1998) pp. 33-34.

26 Rodríguez (1977). 
y sus agentes se encontraran con un valladar infranqueable formado por la libertad de los modernos, que ahora en la obra de estos dos isleños vuelve a desaparecer al colocar a la Administración al lado del individuo desde la cuna hasta la tumba ${ }^{27}$. Y no por estar rodeado el ciudadano por el habitual y amplio acto administrativo que le conecta a diario con los servicios, sino porque se entiende que su libertad será resueltamente la que quiera otorgar el supremo intelecto en que se cifra y condensa la Administración misma. Es esa libertad, de trabajar, de emprender, de resolver como individuo, el que la Administración fiscaliza, orienta, prohíbe y dirige.

Por su parte, en el continente, el pensamiento alemán con raíces profundas en la historia de los pueblos alemanes y con una tradición que se remonta a Bismarck ${ }^{28}$ adoptó, tras los horrores de la II Guerra Mundial, esas políticas cuya mejor expresión doctrinal, por lo que al Derecho Administrativo hace, se encontraría en la obra de E. Fortshoff ${ }^{29}$, siguiendo los pasos de Carl Schmitt, el teórico jurídico más importante de la época nazi. Se trataba, fundamentalmente, de atender a la "procura existencial" (Daseinvorsorge), es decir, condiciones mínimas de existencia vital en las

27 SARTORI (1987).

28 Rodríguez (1979).

29 Forsthoff (1958). El paso resuelto al Estado Social lo da, sin sorpresa posible, el propio Carl Schmitt, como oportunamente recuerda nuestro homenajeado. Vid. L. Parejo Alfonso, "El Estado social administrativo: algunas reflexiones sobre la crisis de las prestaciones y los servicios públicos". Martín-Retortillo (1962), pp. 217-250, califica de "magistral" precisamente tal aportación, que reza así: "El Estado se convierte en 'auto-organización de la sociedad'. Desaparece entonces, como ya hemos indicado, la consabida distinción entre Estado y sociedad, gobierno y nación, desde el momento en que todos los conceptos e instituciones (Ley, presupuesto, autonomía administrativa) construidos sobre dicha premisa comienzan a plantear nuevos problemas. Pero, al mismo tiempo, se opera una transformación más vasta y más profunda. Se organiza la sociedad misma en Estado: el Estado y la sociedad deben ser fundamentalmente idénticos. Con ello, todos los problemas sociales y económicos se convierten en problemas políticos y no cabe distinguir ya entre zonas concretas político-estatales y apolítico-sociales. Todas las antítesis que resultan de la premisa del Estado neutro, como una consecuencia inmediata de la distinción entre Estado y sociedad, y que sólo son casos concretos y manifestaciones metafóricas de esta distinción, cesan por completo (...). La sociedad convertida en Estado se transforma en Estado económico, Estado cultural, Estado previsor, Estado bienhechor, Estado benéfico; el Estado resultante de la auto-organización de la sociedad no puede ya separarse realmente de ella y abarca todo lo social, es decir, todo aquello que guarda relación con la convivencia humana. En él no existe ya sector alguno frente al cual pueda observar el Estado una neutralidad incondicional en el sentido de la no intervención". Sснмітт (1983). 
que el individuo aislado, según la tesis, carecía de poder suficiente para dominar su espacio propio por invasión del mismo por parte de poderes económicos poderosos, por lo que necesitaría permanentemente del auxilio de la Administración ${ }^{30}$. De ahí que se teorizara -traduzco expresamente- la "menesterosidad social" del individuo aislado, es decir, la "insoportabilidad" de luchar aisladamente contra la fuerza de determinados poderes privados, para lo cual resultaba imprescindible, se estimaba, establecer una alianza de protección entre la persona individual y el Estado. Una especie de "nueva devotio"31 por la que, gustosamente, se acepta el vínculo de vasallaje con el nuevo señor, el Estado, para que le defienda de otros feudos dominantes, las grandes compañías de suministros del "círculo vital", ¡cómo resuena el indomable Hegel! , frente a las que el individuo no representa nada. Había que dejar un "espacio vital" en el que la relación entre ese pequeño horizonte y el ciudadano poseedor no tuviera más arco de bóveda que su señor estatal. Entre el ciudadano y el Estado, así, se establecería una alianza en la que el poder protegería y el individuo se liberaría gracias al amparo de su único dueño.

Conviene destacar, llegados a este punto, que la idea de la menesterosidad social está muy lejos de concluir en un camino de libertad transitado por una alianza entre el individuo y los poderes públicos para que éstos logren que los poderosos intereses privados compitan entre sí. No se trata de lograr, more americano, que intervengan las autoridades para conseguir que se respeten las reglas, se introduzca competencia y se sirva al consumidor que es, en definitiva, el ciudadano cuando se relaciona con bienes y servicios. La tesis principal de la procura existencial consiste en afirmar que en el espacio vital del ciudadano moderno solamente la intervención de la Administración consigue dotar al administrado de los bienes que necesita. Se estima que, abandonado a los poderosos intereses privados, dependería en tal manera de los mismos el pobre ciudadano que exclusivamente la Administración está en condiciones de garantizar su atención.

Esta teoría no se preocupa para nada de la provisión libre de los bienes y servicios, sino que estima que dicha provisión ha de estar vigilada, intervenida y sustituida eventualmente por la acción administrativa directa. No es sólo regulación y poder tarifario sobre las empresas suministradoras

30 Martín-Retortillo (1962).

31 RAMOS (1924) p. 7-26. 
de servicios. Es vigilancia, tutela y cuidado paternal sobre el mísero infeliz que es el ciudadano aislado, al cual la Administración ha de adoptar. Y en esa adopción, la Administración Pública, nuevo tutor, si se quiere, inédito "pretor peregrino", poseída de un supremo intelecto, conoce anticipadamente hasta los más mínimos detalles, cuáles serán las futuras necesidades de dicho ciudadano y cómo atenderlas. Posición colectivista, pues, sustituyendo la acción privada por la burocrática.

Como definió Albert Dicey hace ya casi un siglo, el colectivismo consiste en "el gobierno de los expertos y funcionarios para el bien de la gente, quienes saben o creen que saben lo que es bueno para el pueblo, mejor que los no expertos o que la masa de la propia gente ${ }^{\prime \prime 32}$. Nada de delimitar el ámbito de la Administración, que desde luego es imprescindible en el juego necesario entre política y técnica. Tan perverso es pretender que el político conoce la técnica como que el técnico decida políticamente. El papel ancilar y continuo de la Administración es esencial, pero la tecnocracia no es en modo alguno una fórmula mínimamente aceptable; igualmente, la sustitución indebida del técnico por el político es simplemente el anuncio de catástrofe y corrupción. Garantizar pues la neutralidad, objetividad e imparcialidad funcionarial es clave; de ahí su estatuto en el orden continental, inclusive en el británico, y el consecuente peligro de sustituirle progresivamente por empleados meramente contratados, susceptibles de expulsión en caso de incomprensión del arbitrio del político (incluso de la amenaza, real por demás, de la bajada de emolumentos en supuesto de criterios técnicos diferentes del Plaisirs du Roi de tantos regentes, con que determinados cuerpos de funcionarios sufren la presión política, verbi gratia, los Secretarios e interventores locales por parte de los indicados alcaldes).

Así pues, la desconfianza en la provisión privada de los bienes y servicios es total. Y no le basta a esta teoría con los poderes de regulación, disciplina, vigilancia y control de la Administración Pública. Exige, inclusive, la propia definición del bien a prestar, sus caracteres, sus modos de explotación, en fin, todo lo relativo a la provisión del bien. Esta es la base de la recién inaugurada "remunicipalización", que bien estudiada por los administrativistas está ofreciendo penosos ejemplos en boca de los políticos por pura ignorancia, pretendiendo redescubrir mediterráneos en lo que

32 Dicey (1914). Posteriormente hay otras ediciones con inclusión de un epílogo del propio autor. 
eran concesiones del servicio público ${ }^{33}$. No se ha concretado en este movimiento una línea clara que indique cuándo y por qué la Administración utiliza la gestión directa. A mi juicio, como he tenido ocasión de explicar $^{34}$, es ciertamente buena línea de orientación mostrar los bienes públicos (en sentido económico) que claramente exigen gestión directa por la Administración. Definir esos bienes públicos de la mano de la teoría económica, pues, se convierte en un asunto imprescindible.

En Francia, la formulación cartesiana, propia del pensamiento burocrático galo, haría que fuera desde la ENA como se lanzaría la idea de que el poder burocrático de las elites administrativas, permitiría planificar la totalidad del país, su economía, su suelo, mediante acciones que, mecánicamente, inducirían al logro de los resultados propuestos como si de un mecano se tratase. Tiene interés recordar este punto, porque el espíritu burocrático imprime carácter a la obra y la acción de la Administración francesa, imponiendo así la ley y su gestión por los dirigentes como medio de solución unitaria y directa de todos los problemas. La ley y el decreto, como fórmula mágica de la ciencia política y jurídica, logra objetivos unitarios, de un solo golpe, eliminando toda discusión y experiencia, amén del importante caudal de la escuela del servicio público, infatigable trabajadora en su misión de convertir al Estado en una empresa. Esto es algo sorprendente por proceder del denominado "socialismo jurídico", que en sí mismo supuso la apertura definitiva a un modelo que, paradójicamente, coincidía con sus antípodas ideológicas, como es el norteamericano.

No deja de ser curioso que este análisis, tan influyente en nuestro país a través de una generación de administrativistas, se detuviera en este punto sin tener para nada en cuenta otras variables de interés. Entre ellas, cabe hacer figurar que esa teoría no refleja otra cosa que una economía estática, en la que el reparto de los mercados de suministros de servicios básicos estaba cartelizada debido precisamente a la acción del propio Estado que había nacionalizado o intervenido fuertemente gran parte de ellos, y que por otra parte, la alianza era en realidad entre tales poderes económicos y el propio Estado atrapado por ellos, en una operación típica de "secuestro del legislador" o "captura del regulador". Es decir, en un juego

33 Por todos vid. Tornos (2016), Gimeno (2016), Castillo (2016), Villar (2016), Pardo (2017), Villar (2017), Mellado (2017), Serrano (2017), Arbués (2017), Sanaú (2017) y Flores (2017).

34 SORIANO (1993). 
"intra-muros" entre la Administración Pública y los poderes económicos privados que dominaban a aquélla, trufando con sus intereses propios los objetivos públicos identificadores del interés general ${ }^{35}$.

La economía de posguerra, junto con la influencia del pensamiento de Carl Schmitt, está en la base de toda esta teoría. El maniqueo entre "amigos" y "enemigos" vuelve a reproducirse aquí. La Administración es amiga del ciudadano y las empresas, al menos las que provean esta clase de servicios necesarios, son sus enemigas. Habrá que convivir con ellas, a falta de otra teoría, salvo la marxista, pero dominándolas absolutamente. Es evidente la influencia sobre el pensamiento de raíz tecnocrática, que está en la base desde el principio en las formulaciones del ordenamiento económico, urbanístico, etc., es evidente.

La mezcla de poder y dinero que se generó era debida justamente a la mescolanza indebida entre acción pública y acción privada, de modo que la "economía mixta", típica de esta forma de Estado, pasa por convertir al Estado en mercader y a los mercaderes en Estado. Al no trazarse esa raya invisible entre Estado y sociedad, la difuminación de la misma implicaba, a su vez, la interpenetración de uno y otra, confundiendo lamentablemente sus papeles en beneficio exclusivo de determinados agentes burocráticos y de sus clientelas económicas.

El Estado se constituía en agente o inclusive en protagonista económico del mercado, desacreditando así tanto al mercado como, lo que resulta mucho más grave, al propio Estado. Pensar realmente que políticos y funcionarios son operadores económicos sería una broma jurídica estupenda, si no tuviera las consecuencias gravísimas que tiene para el propio Estado. Los intereses generales pasan así a desviarse continuamente hacia intereses particulares. El Estado convertido en empresario implica, por de pronto, la eliminación del riesgo implícito en toda operación mercantil al utilizar el instrumento legislativo, la ley, como parte del negocio. O mejor dicho, el Estado en estas condiciones traspasa ese riesgo al conjunto de la sociedad a la que convierte, vía impuestos, en accionistas forzosos de

35 OLsON (1992). Los procesos de "captura o secuestro" se dan obviamente también en el caso de las agencias independientes, como destacó STIGLER (1980), pp. 101 y siguientes, pero la agencia ha de justificar su independencia, mientras que la Administración indiferenciada puede incluso presentarse y lo hace habitualmente como "defensora del sector". 
su propia aventura particular. $Y$ el acto administrativo pasa a ser objeto de deseo y botín, por lo que no debe extrañar que la corrupción anide precisamente, en la compra del acto administrativo.

Esta conversión del Estado en operador económico es una clara dificultad al proceso liberalizador de la economía al actuar la Administración como juez y parte en los mercados, desnaturalizando el libre intercambio y la mutua cooperación social realizada a través de las transacciones económicas normales.

Toda Europa, continental e isleña, se vio inmersa en esta vorágine intervencionista, arrumbando con alegría las viejas libertades económicas, pese a que la salvación del Viejo continente vino del Nuevo, preñado de otras ideas, la competencia entre ellas, que viajó en las mochilas de los soldados norteamericanos que liberaron a Europa de la dictadura.

Cierto que no hay mercado sin Estado ${ }^{36}$. Los trabajos de STIGLITZ ${ }^{37}$ y SAN$\mathrm{DEL}^{38}$ aportan bastante luz sobre los excesos de un capitalismo sin ley.

Sin el poder del Estado, ejercido normalmente a través del Legislativo mediante leyes generales o inclusive de orden especial; del poder Administrativo, mediante reglamentos y regulaciones y eventualmente resoluciones y poder disciplinario, simplemente el mercado no existe, simplemente es la ley de la selva, el reino de la estafa y corrupción. Ello exige desde luego un poder administrativo robusto, bien dotado de funcionarios preparados (no de meros empleados públicos seleccionados ideológicamente o inclusive partidistamente) y estables, y reglas claras basadas en la transparencia, objetividad, veracidad, etc.

No cabe en modo alguno que el mercado sustituya al Estado sin pérdida completa y derrumbamiento de la propia sociedad, lo cual no significa dejar de apoyar la libertad de iniciativa, de empresa y de mercado, al servicio común desde luego, evitando, especialmente en el capitalismo trasnacional, que utilicen su poder para dañar a sociedades inermes ante

36 Soriano (1998), donde se abunda en esta idea, evitando la entrega de la sociedad directamente a los poderes económicos a través de una enérgica formulación de las administraciones públicas.

37 Stiglitz (2012).

38 SANDel (2013). 
su invasión. Las prohibiciones y sanciones tienen su lugar claro en la historia de las ideas administrativas y bien pueden ser en muchas ocasiones la solución frente a los atentados a la dignidad de muchas personas indefensas ante las sesgadas políticas empresariales.

En definitiva, más bien parece que la solución desde el Estado de Derecho continúa siendo la de proceder a fijar mediante leyes claras las reglas del juego, basado siempre en la dignidad humana, en el realismo de aproximación a la misma, y que el sentido de justicia sea logrado, dentro de su dificultad, con la máxima extensión ${ }^{39}$. Y siempre con las herramientas clásicas, acercándose con ojos claros a la realidad, evitando entontecerse con el ruido mediático o de las redes sociales, comprobando los hechos, números y datos para saber el coste de las políticas y su posibilidad en el corto plazo. En fin, volviendo a un examen clásico que, basado en fundamentos bien establecidos, permita abordar con ética y solvencia los temas de nuestro tiempo.

Pero no siempre se ha hecho así.

El imponente pensamiento alemán, bien asentado por otra parte en la historia común de los pueblos alemanes, se fundamenta en la visión colectivista y gremial que está en las raíces de su más íntimo derecho ${ }^{40}$. Estudiaremos en otro trabajo, con algún detenimiento, lo que supuso esta Welltalschaung que tan dramáticos efectos habría de tener en Alemania y por extensión en el resto de Europa, al constituir una de las bases de los conflictos, conflagraciones y tensiones que Germania originó en el resto del continente y aún del mundo. Ciertamente se actuó de buena fe, como demuestra la noble obra de Herman Heller, quien quizás por fallecer en Madrid ha alimentado una buena saga de seguidores de su obra en nuestro país. Pero reconociendo que esa obra está preñada de bondad, sus carencias económicas y la tendencia hacia una cierta y clara ideologización del Derecho la hace acreedora de un idealismo platónico que coincide desde luego con gran parte del pensamiento hispano, carente, creo, de realismo. Siempre falta a este tipo de pensamiento poder hacer los números, incorporar datos, mirar la realidad antes de adoptar una decisión, falta en gran medida la reflexión económica.

39 SEN (2009).

40 De Ruggiero (1944). 
Ciertamente sería irreal, y por tanto desde esta perspectiva profundamente injusto y equivocado, no reconocer que, profundizando en una línea política que ya venía de principios de siglo cuando se funda en 1908 el Instituto Nacional de Previsión, el Estado Social ha potenciado una sanidad que, sin hipérbole, se encuentra entre las mejores del mundo occidental. Y ha extendido, ya con diferente éxito, la educación primaria y universitaria. Por tanto, en determinados sectores globales, generales, donde se ha sabido combinar ideología con necesidad real, el éxito ha acompañado a la operación. La cuestión a tratar es la indebida extensión de tales ideas a la totalidad de los sectores y de los individuos, ya que éstos pasan de ser ciudadanos a ser "administrados", no siendo casual que sea éste el término empleado por el artículo 149.1.18 de la Constitución. Se ha convertido pues en bienes públicos, al menos conceptualmente, a la sanidad y a la educación. No cabe exclusión pues de sus prestaciones dentro del esquema ordinario de prestaciones, obviamente con la consecuente atribución presupuestaria de la financiación correspondiente, aunque como toda conversión mediante la ley, de bienes privados en bienes públicos, siempre existen límites y excepciones.

La cuestión es la pretendida extensión de tal Estado Social a otro que simplemente no es soportable financieramente sin la eliminación prácticamente total de la libertad individual.

Esta óptica colectivista de la sociedad da por supuesto que el Estado ha de redistribuir la riqueza entre unos y otros miembros. El Estado se convierte en un ente de reparto. El principio de igualdad se entiende resueltamente como un ariete que dirige el Estado y que en España se ha traducido, por los partidos políticos, en un igualitarismo que pretende eliminar las diferencias, especialmente si se basan en el mérito y la capacidad. Se estima así que, con independencia de los objetivos públicos a los que aplicar los recursos e ingresos que el Estado obtenga, es bueno, en sí mismo considerado, proceder a la nivelación económica mediante la técnica fiscal y administrativa en general. Se juzga que la riqueza es una situación "mala perse" y que es deber ético del Estado - a su vez el más ético de todos los entes-acabar con esa desigualdad. Se hace buena aquí, en su aplicación en España, la vieja tesis de Weber sobre el espíritu del capitalismo frente al catolicismo ${ }^{41}$.

41 Weber (2012) y Troeltsch (1958). 
Por ello, inmediatamente, el Estado Social así generado actúa primero sobre los ingresos y luego se preocupa del gasto (cuando debería ser al revés, ya que la planificación fiscal exige conocer anticipadamente lo que se desea financiar y solamente después abordar cómo hacerlo, ya que así se sabe lo que se quiere). Con lo cual, el resultado fatal es siempre que no se pueden bajar los tributos, que siempre el gasto aumenta de forma exponencial y que se "descubren" permanentemente nuevas y crecientes necesidades que "ha de atender" el aparato público. Esa coacción forzosa descubre en el solemne nombre de "solidaridad" la clave moral para utilizarla compulsivamente. Las obligaciones solidarias son, no lo olvidemos, aquellas que establecen un vínculo o comunión entre todos los sujetos relacionados, en cuya virtud se puede exigir responsabilidad a cualquiera por la acción u omisión de todos los demás. Así el deudor solidario responde siempre, haya tenido o no parte en la acción u omisión de cualquiera de los miembros a los que está unido por ese vínculo. La responsabilidad se comparte en potencia, y en acción, además, se sufre o se puede sufrir incluso individualmente. Es una extensión de la culpabilidad por la acción de otro; una proyección del pecado original. Y esa extensión hace que todos sean culpables o, al menos, responsables de cualquier evento que les suceda a los demás. El vínculo o nudo es, en la solidaridad teorizada políticamente, forzoso y coactivo. No es un vínculo aceptado voluntariamente, sino impuesto a la fuerza por un tercero. $Y$ ese tercero, el Estado, obtiene así las rentas del árbitro de la relación. A mayor poder, mayor renta y así en una espiral sucesiva.

Los distintos sujetos que forman parte del conjunto solidario responden todos o, lo que es igual, no responde ninguno. $\mathrm{O}$ al menos, puede no responder ninguno, salvo, claro está, aquellos que motivados por su propia iniciativa personal acaban pagando siempre por los demás. En un contexto de solidaridad múltiple y forzosa, y sin conexión con objetivos públicos definidos, hacen su agosto los free riders, toda clase de polizones, piratas, vagos y aprovechados ${ }^{42}$. El pasajero sin billete encuentra aquí fácilmente buque en cuya bodega puede partir. El contrabando, es decir, saltarse la norma (evasión fiscal, información urbanística privilegiada, modificación puntual de los planes de urbanismo, contratos del sector público adjudicados irregularmente, por ejemplo) es un elemento que surge espontánea-

42 Por usar formas descriptivas utilizamos esas expresiones. Un supuesto clarividente de cómo actúan estas fórmulas económicas incentivadas por la existencia de normas en TROELTSCH (1980). 
mente al estar enormemente incentivado en un cálculo generalizado de ganancias y beneficios que suele vencerse del lado del riesgo de incumplir antes que de la servidumbre de sufrir. Y los sujetos cumplidores pasan así a la condición de héroes, esto es, de sujetos que tienen un comportamiento anormal consistente en asumir por sí la carga de todos los demás, lo cual constituye una conducta antieconómica y un enorme sacrificio personal; así emprender tareas por su riesgo y cuenta en un contexto de "solidaridad" implica asumir desenvolverse en un ambiente hostil y contrario a la aventura personal, no exenta de múltiples riesgos.

Es así como surge un gasto público auto-justificado por la nivelación económica que implica y al que hay que dar alguna salida, incluyendo desde luego el despilfarro, la holgura y el ensanche de la acción pública en competencia con la privada; los más imaginativos y aun descabellados proyectos y gastos públicos impuestos a la fuerza como efímeras realizaciones, a veces delirantes y faraónicas, casi siempre no rentables ${ }^{43}$. Incluso desde la teoría de la organización simplemente ya no se puede gestionar con un mínimo de racionalidad los recursos detraídos que alcanzan ya una proporción del PIB simplemente inasumible para cualquier organización. Y ahí se encuentra una parte de la explicación de la crisis económica more hispánica, negando en 2007 y 2008 la existencia de la misma, y abocándonos al borde del precipicio en 2011 en términos de los que todavía tardaremos en recuperarnos.

Este clima es directamente contrario a la liberalización económica. Surge en tal ambiente un conjunto complejo de lazos que impiden abordar con claridad los procesos liberalizadores. Tales vínculos son del siguiente tenor: a) a mayor gasto público, mayor necesidad de empleados públicos a los que hay que dar cometidos y tareas, las cuales pasan, muy principalmente, por incrementar el número y dificultad de las regulaciones, que es como maximizan su trabajo y la validez de sus objetivos internos propios. La burocracia es directamente beneficiada del aumento del gasto público y el crecimiento de la misma está en relación directa con el incremento de dicho gasto; b) a mayor gasto público, mayor es el número de ayudas, subvenciones, auxilios a empresas y empresarios. De esta manera, la subordinación de éstos a los poderes públicos es total y se produce una "alianza en las antípodas" entre la Administración y la empresa. La

43 Termes (1997). 
caza de recompensas administrativas pasa a ser un botín especializado de un gran número de empresas. Así, éstas se convierten en los primeros interesados en que no se produzca la liberalización de los sectores económicos "devocionarios" de la ayuda pública; c) a mayor gasto público, mayores incentivos al despilfarro con tales recursos públicos. Aparecen enormes cúmulos de actividades, impensables en un escenario de austeridad, consistentes en múltiples casos en desarrollar el panem et circenses con dinero público; d) a mayor gasto público, mayores incentivos a entrar directamente en los mercados y proveer directamente también los bienes y servicios por las autoridades públicas mediante empresas públicas, que viven del presupuesto y crean así grupos y colectivos directamente interesados y beneficiarios del mantenimiento y aún aumento del gasto del que tan bien viven.

Dentro del marco moral, con importantes repercusiones psicológicas, importa destacar que una dificultad no menor se encuentra en la necesidad no solamente de los políticos, sino también de los individuos en una sociedad, de "seguir la corriente", de no distinguirse y de ser aceptados dentro de la comunidad en la que viven dentro de un orden de referencias que les distinga precisa y claramente, como formando parte de la cultura establecida. La estrategia de la "persuasión" de los grupos de presión (aumentada ad infinitum por las redes sociales) pasa precisamente por difundir y propagar repetidamente la especie de que se trata, en la seguridad que se logrará el objetivo propuesto, basándose en la coerción que supone la existencia de autoridades difusas o carismáticas - depende de la estrategia-, con la consecuente aceptación acrítica por parte del individuo de la ideología - conjunto de creencias que tienen una explicación inmediata para todo-que éstas difunden. El individuo, además, procurará deprimir su umbral de resistencia para ganar en aceptación y no distinguirse para nada de los demás miembros del grupo, especialmente si por sus condiciones personales tiene alguna peculiaridad o simplemente alguna diferencia de origen o de cualidad respecto del grupo. En este último caso, la necesidad de aceptación pasa por la más íntima traición a sí mismo (aunque, sin tanta exigencia, no se necesita una auténtica traición, y basta una simple falsificación ideológica) a sus orígenes, hasta buscar la adhesión racional a toda costa, pese a tener que pagar, dependiendo de su conciencia, un precio más o menos alto por esa inquebrantable demostración de apego. Un caso de isomorfia social que actúa asimismo sobre la ideología. 
Recuerda Anthony de Jasay ${ }^{44}$ "que las preferencias por acuerdos políticos de la sociedad son en gran medida producidas por esos propios acuerdos, [...] la opinión de Max Weber de que los resultados históricos son en gran medida no intencionados merece un prejugé favorable como la más prometedora aproximación a muchas de las relaciones entre Estado y súbdito".

SCHELLING ${ }^{45}$ Ilama "comportamiento contingente" a la necesidad de aceptar una opinión a partir de la percepción que se tiene de la opinión de los demás, y los trabajos de George Akerlof recuerdan que el individuo hace un balance entre la utilidad derivada de seguir una creencia, aunque le resulte perjudicial, y la utilidad percibida por todo el grupo de cuyo "código de honor" forma parte.

Cuando una idea coincide con la de la mayoría, la posibilidad de influencia es muy superior y pueden ganar así, duraderamente a cualquier minoría. La importancia de los mitos, lugares comunes, especialmente hoy el victimismo político, social, histórico, cobra así un papel fundamental como multiplicador de la idea, por errónea que sea y por cruel y costoso que sea imponerla a la minoría.

La difusión de las ideas, sin embargo, puede adoptar también la forma de "conformismo social" imponiéndose contra toda razón humana, incluso la más elemental, cuando minorías compactas y herméticas penetran el tejido de sociedades abiertas, indefensas ante ataques para el que no están preparadas. Es un caso de "lógica de la acción colectiva", incluso cuando se trata de acciones perversas. La complicidad social, lograda muchas veces por la indiferencia, la pasividad, cuando no el miedo, puede dar lugar a perversiones de la razón y de la humanidad más elemental. Se actúa así como polizones de buques que habría que poner en cuarentena, ya que se ofrecen pervertidamente males públicos en vez de bienes públicos, sobre los que penetra, hasta rasgar totalmente la envoltura, la presión de los grupos organizados.

Timur Kuran explica que la formación de opiniones colectivas - conservadurismo colectivo- exige la falsificación de las preferencias, es decir, la modificación de la inclinación que los individuos tienen de una idea

44 De Jasar (1993).

45 Sigo aquí a la exposición de FraILE (1998) pp. 209 y siguientes. 
o programa como consecuencia de un sistema social de gratificación y penalización moral. Fraile Balbín recuerda muy a propósito que el estudio de Kuran ayuda a explicar la inercia de las opiniones colectivas y su evolución en función de la distribución inicial percibida por los individuos de esas opiniones. Lo más importante de este análisis es que ayuda a explicar la doble función de los grupos de interés en sus estrategias de ofuscación: por una parte, difundiendo la opinión que favorece a sus propósitos, y más importante aun, anunciando su aceptación mayoritaria para rebajar el "umbral" de aceptación general; y en segundo lugar, difundiendo el sistema de reputación y sanciones morales, un "sistema público de creencias" que condiciona las preferencias individuales ${ }^{46}$.

Es evidente que ese ámbito, ese contexto, determina en alguna medida la competitividad de las industrias y firmas de las distintas naciones, y la causa de la riqueza y pobreza de las naciones, quizás, al decir de Malthus en su carta a Ricardo, "el gran objeto de todas las cuestiones en la Economía Política" ${ }^{47}$. Ninguna Nación es competitiva en todo ${ }^{48}$. La especialización y jerarquía de las distintas ventajas competitivas, dependen en medida no desdeñable de factores institucionales, cuyo estudio, mejora y cambio, comienza ahora a ser cometido también de los economistas, junto con sociólogos, juristas y otros expertos. A su vez, como en un efecto reflejo, los análisis de los economistas, principalmente, sirven para poner de manifiesto aspectos de las tendencias, modas, instituciones, hábitos y conductas que de otra forma permanecerían en penumbra. Los muy jugosos e incisivos estudios de BECKER o STIGLER sobre múltiples aspectos de la conducta humana, en relación con los hábitos, tradiciones y cultura, explican a su vez, en retroalimentación, por qué se forman determinadas instituciones ${ }^{49}$.

46 Fraile (1998) p. 210.

47 Carta del 26 de enero de 1817, citada por SKIDELSKY (1994), LANDES (1998) y sobre todo LANDES (1988), donde claramente establece las bases de la teoría que dio lugar a la Revolución industrial. Últimamente, insistiendo en esta tradición anglosajona de inquirir sobre las causas de la pobreza y riqueza de las naciones, vid. ACEMOglou y Robinson (2012).

48 PORTER (1990).

49 Todo jurista debería, con algo de ayuda, leer las deliciosas páginas de Gary S. Becker, recopiladas en BECKER (1995), en las que encontrará una audaz apuesta por la Economía como ciencia explicativa de la conducta humana, y la no menos atractiva de STIGLER (1986), donde se explica la racionalidad e irracionalidad de las normas reguladoras de sectores económicos y la lógica de la acción colectiva, vista desde el comportamiento económico de los individuos. 
El nuevo interés de los economistas por el análisis de las instituciones, y el intento serio de cuantificar el orden de preferencias, es un potente y nuevo instrumento de examen de las dificultades de los procesos liberalizadores al permitir a los juristas tener una mejor y más penetrante descripción de la realidad social sobre la que actúa la norma y realizar evaluaciones no arbitrarias del influjo del Derecho sobre la sociedad. Hasta ahora, no obstante, el trabajo de los economistas sobre los mecanismos de legitimación de la Administración Pública son más bien escasos y, desde luego, prácticamente inexistentes en lo que a la actuación de sus potestades hace en sectores que, regulados por el Derecho Administrativo, están como los personajes de Pirandello.

\section{BIBLIOGRAFÍA CITADA}

Acemoglou, Daron y Robinson, James (2012): Why Nations Fail (New York, Editorial Random House).

AmArTYa, Sen (2010): La idea de la justicia (Bogotá, Editorial Taurus).

ARbuÉs, Fernando (2017): "Los procesos de transición en la 'remunicipalización' del servicio urbano de agua", El Cronista del Estado Social y Democrático de Derecho, n 69, pp. 44-49.

BeCKer, Gary (1995): The Essence of Becker (Edited by Ramón Febrero y Pedro Schwartz)(California, Editorial Stanford).

BeverIDGE, William (1944): Full Employment in a Free Society (Londres, Editorial W.W. Norton).

Buchanan, James y Wagner, Richard (1983): Democracy on Deficit: The Political Legacy of Lord Keynes. Nueva York. Versión española (New York, Editorial Academic Press).

Buchanan, James (1997): Has Economics Lost its way? Reflections on the economists' enteprise at century's end (Fairfax, Editorial Institute for Humane Studies, George Mason University). 
CASTILLO, Federico (2016): "Remunicipalización de servicios locales y situación del personal de los servicios rescatados", El Cronista del Estado Social y Democrático de Derecho, n $^{\circ}$ 58-59, pp. 72-9.

Cerroni, Umberto (1972): La libertad de los modernos (Barcelona, Editorial Colección Novocurso).

Constant, Benjamin (1819): "Discurso sobre la libertad de los antiguos comparada con la de los modernos", Revista de Estudios Públicos $n^{\circ} 59$ del año 1995.

De JASAY, Antony (1993): El Estado. La lógica del poder político (Madrid, Editorial Alianza Universidad).

De Ruggiero, Guido (1944): Historia del Liberalismo Europeo (Madrid, Editorial Pegaso).

DiCEY, A.V. (1914): Introduction to the Study of the Law of the Constitution (Indianápolis, Editorial Liberty/Classics).

DiEz, Luis (1973): El liberalismo doctrinario (Madrid, Editorial Centro de Estudios Constitucionales).

FLORES, Luis (2017): "Privatizaciones y remunicipalizaciones: experiencias en el Ayuntamiento de Sevilla", El Cronista del Estado Social y Democrático de Derecho, n 69, pp. 6o-71.

Forsthoff, Ernst (1958): Tratado de Derecho Administrativo. Traducción española (Madrid, Editorial Instituto de Estudios Políticos).

Fraile, Pedro (1998): La retórica contra la competencia en España (1875-1975) (Madrid, Fundación Argentaria).

Gimeno, José (2016): "Remunicipalización de servicios locales y Derecho comunitario", El Cronista del Estado Social y Democrático de Derecho, $\mathrm{n}^{\circ}$ 58-59, pp. 50-71.

HAYEK, Friedrich (1975): Full Employment at Any Price? (Londres, Institute of Economic Affairs). 
Hutchison, Terence (1977): Keynes v. "The Keynesians". Comentarios de Lord Kahn y Sir Austin Robinson (Londres, Institute of Economic Affairs).

KeRSHAW, Ian (1983): Popular Opinion and Political Dissent in the Third Reich. Bavaria, 1933-45 (Oxford, Oxford University Press).

_ (1990): Weimar: Why did German Democracy Fail? (Londres, Weidenfeld and Nicolson).

—_(2017): Hitlerel'enigma del consenso (8º Edición, Roma, Edizioni Laterza).

Klappenbach, Augusto (1998): “Libertad, Liberalismo y Abstracción", Claves de Razón Práctica, $\mathrm{n}^{\mathrm{0}}$ 85, pp. 33-34.

Landes, David (1998): The Wealth and Poverty of Nations (New York, Editorial W.W. Norton \& Company).

- (1988): The Unbound Prometheus. Technological Change and Industrial Development in Western Europe from 1750 to the Present ( $8^{\circ}$ Edición, Cambridge, Editorial Massachusetts).

Martín-Retortillo, Lorenzo (1994): “Keynes y la nueva Ley sobre las Administraciones Públicas", Revista Española de Derecho Administrativo, $\mathrm{n}^{\mathrm{o}}$ 82, pp. 201-206.

Martín-Retortillo, Cirilo (1962): “La configuración de la Administración Pública y el concepto de "Daseinvorsorge "”, Revista de Administración Pública, $\mathrm{n}^{\mathrm{o}} 38$, pp. 35-66.

MANCur, Olson (2001): Podery prosperidad. La superación de las dictaduras comunistas y capitalistas (Madrid, Editorial Daron Acemoglu).

MAYNARD, John (1937): The Economist as Saviour 1920-1937 (Verlag nicht ermittelbar, Erscheinungsort nicht ermittelbar).

—— (1988): Ensayos de Persuasión (Barcelona, Editorial Crítica).

—_ (1996): Esperanzas frustradas 1883-1920 (Madrid, Alianza Editorial). 
Mellado, Carlos (2017): "La reversión a la gestión directa de servicios públicos: problemas laborales", El Cronista del Estado Social y Democrático de Derecho, no 69, pp. 22-35.

MuÑoz, Santiago (2016): "La búsqueda de la felicidad", El Cronista del Estado Social y Democrático de Derecho, $\mathrm{n}^{\circ}$ 58-59, pp. 14-23 y 56-69.

Novick, Sheldon (1990): Honorable Justice: The life of Oliver Wendell Holmes (Birmingham, Legal Classics Library).

Olson, Mancur (1992): La lógica de la Acción Colectiva. Bienes Públicos y la Teoría de los grupos (México, Editorial Limusa).

PAREJO, Luciano (2000): "El Estado social administrativo: algunas reflexiones sobre la crisis de las prestaciones y los servicios públicos", Revista de Administración Pública, $\mathrm{n}^{\mathrm{O}}$ 153, pp. 217-250.

PeAcock, Alan (1995): Elección pública. Una perspectiva histórica (Madrid, Editorial Alianza).

POPPER, Karl (2006): La sociedad abierta y sus enemigos: Con una adenda del autor (Barcelona, Editorial Paidós Planeta).

Porter, Michael (1990): The Competitive Advantage of Nations (Londres, Editorial Macmillan).

PARDo, José (2017): "El movimiento remunicipalizador. Experiencias y expectativas", El Cronista del Estado Social y Democrático de Derecho, $\mathrm{n}^{\circ} 69$, pp. 4-11.

Ramos, José (1924): "La devotio ibérica. Los soldurios", Anuario de Historia del Derecho español, vol. I, pp. 7-26.

Robinson, James (2012): Por qué fracasan los países: los orígenes del poder, la prosperidad y la pobreza (Barcelona, Editorial Deusto).

Rodríguez, Francisco (1977): Historia de la Democracia. De Solón a nuestros días (Madrid, Temas de Hoy). 
Rodríguez, Álvaro (1979): Introducción a la obra de Paul Laband. 'El Derecho Presupuestario' (Instituto de Estudios Fiscales, Madrid).

SANAú, Jaime (2017): “Los aspectos sociales en la gestión pública y privada del agua en España", El Cronista del Estado Socialy Democrático de Derecho, $\mathrm{n}^{\circ} 69$, pp. 50-59.

SANDEL, Michael (2013): What Money can't buy. Traducción de 2013 a cargo de J. Chamorro. "Lo que el dinero no puede comprar. Los límites morales del mercado. Debate" (Barcelona, Editorial Debate).

SARTORI, Giovanni (2015): La Democracia en 30 Lecciones (México, Debolsillo).

__ (1987): Teoría de la democracia (Madrid, Alianza Editorial).

SARTORI, Giovanni y Petit, Núria (2016): La carrera hacia ningún lugar (Barcelona, Editorial Taurus).

SEN, Amartya (2009): The Idea of Justice (Cambridge, Belknap Press of Harvard University Press).

SeRrANO, José (2017): "El debate sobre la gestión pública o privada del servicio urbano de aguas", El Cronista del Estado Social y Democrático de Derecho, $\mathrm{n}^{\circ}$ 69, pp. 36-43.

Severo, Massimo (1977): "Stato Sociale: una nozione inutile", Il Político, vol. $42, \mathrm{n}^{\mathrm{O}} 2$, pp. 205-22.

Schmitt, Carl (1983): La defensa de la Constitución (Madrid, Tecnos).

SKIDELSKY, Robert (1994): The Economist as Saviour 1920-1937 (New York, Editorial Allen Lane).

SMITH, Adam (2004): La teoría de los sentimientos morales (Madrid, Alianza Editorial).

Soriano, José-Eugenio (1993): Desregulación, Privatización y Derecho Administrativo de Bolonia. Real Colegio de España en Bolonia (Zaragoza, Editorial Cometa). 
__ (1998): Derecho Público de la Competencia (Editorial Marcial Pons).

Stigler, George (1980): "El proceso de regulación económica", ICE: Revista de Economía, $\mathrm{n}^{0}$ 557, enero de 1980, pp. 101-111.

- (1986): The essence of Stigler (Edited by Kurt R. Leube y Thomas Gale Moore) (Stanford, Hoover Inst. Pr.).

Stiglitz, Joseph (2012): The Price of Inequality Norton. Nueva York, Traducción de Alejandro Pradera de "El precio de la desigualdad" (New York, Norton).

Termes, Rafael (1997): Del Estado de Bienestar a la sociedad de Bienestar (Madrid, El Escorial).

TORNOS, Joaquín (2016): “La remunicipalización de los servicios públicos locales. Algunas precisiones conceptuales", El Cronista del Estado Social y Democrático de Derecho, $\mathrm{n}^{\circ}$ 58-59, febrero-marzo de 2016.

TroeltsCH, Ernst (1958): Protestantism and Progress; a Historical Study of the Relation of Protestantism to the Modern World (Boston, Beacon Press Boston).

- (1980): "Los costes en bienestar de los aranceles, los monopolios y el robo", ICE: Revista de Economía, enero de 1980, pp. 89 y siguientes.

VARGas, Mario (1998): “Refutación a Kaplan", Diario El País, 19 de julio de 1998.

VICO, Giambattista y VenEZIANI, Marco (1708): De nostritemporis studiorum ratione (Nápoles, L.S. Olschki).

VIEHWEG, Theodor (1964): Tópica y jurisprudencia (Madrid, Editorial Taurus).

VILLAR, Francisco (2016): "Principios de sostenibilidad y estabilidad presupuestaria en la gestión de los servicios públicos locales", El Cronista del Estado Social y Democrático de Derecho, n 58-59, pp. 96-106. 
_- (2017): "Las tarifas por la prestación de servicios públicos: ¿Una categoría inconstitucional?", El Cronista del Estado Social y Democrático de Derecho, $\mathrm{n}^{\circ} 69$, pp. 12-21.

VOLPE, Giuseppe (1977): L’Ingustizia delle Leggi (Milán, Giurisprudenza costituz.-Quaderni N.S.).

Weber, Max (2012): La ética protestante yel "espíritu" del capitalismo. Traducción de Joaquín Abellán García (Alianza Editorial, El Libro De Bolsillo). 